\title{
EVALUATION OF SHEAR STREGNTH DEGRADATION OF RC COLUMN SUBJECTED TO CYCLIC LOADING
}

\author{
LI FU ${ }^{*}$, HIKARU NAKAMURA ${ }^{*}$, HIROKI FURUHASHI ${ }^{*}$ YOSHIHITO YAMAMOTO* \\ AND TAITO MIURA* \\ *Nagoya University \\ Civil and Environmental Engineering, Nagoya, Japan \\ e-mail: fu.li@g.mbox.nagoya-u.ac.jp
}

Key words: Shear failure after yielding, Shear strength degradation, 3-D RBSM, Cyclic loading

\begin{abstract}
When a reinforced concrete (RC) member is subjected to cyclic loading, the shear failure after flexural yielding of tension reinforcing bars (called as shear failure after flexural yielding in this study) is often observed at a small deformation, although it ordinarily suffers flexural failure and shows good deformation ability under monotonic loading. This study presented a numerical method to quantitatively evaluate shear strength degradation of RC member utilizing three dimensional Rigid-Body-Spring-Model (3-D RBSM). The behaviors of a RC column subjected to cyclic loading and repeated loading on one side were simulated by 3-D RBSM, and the behaviors of shear strength degradations were quantitatively evaluated. As a consequence, the different degradation rate of shear strength between cyclic loading and repeated loading on one side was clarified, and the reasonability of the numerical method was confirmed by comparing numerical shear strength degradation curve with previously statistically proposed degradation curves based on the test results.
\end{abstract}

\section{INTRODUCTION}

In the seismic design for a RC member, one of the basic requirements is that brittle shear failure should be prevented and the shear strength exceeds the shear demand corresponding to the flexural strength $[1,2,3]$. Although a good designed RC member under monotonic loading ordinarily suffers flexural failure and shows good deformation performance, if it is subjected to cyclic loading, the load carrying capacity often decreases at smaller deformation after the flexural yielding of tension reinforcing bars and ultimately shear failure occurs. Since the deformation ability of RC member is significant in seismic deformation-based design, many researchers have investigated the influences of several factors such as web reinforcement ratio, tension reinforcement ratio, axial load and shear span-to-depth ratio on the ultimate deformation ductility of RC member by numerical and experimental studies $[4,5,6,7$, 8].

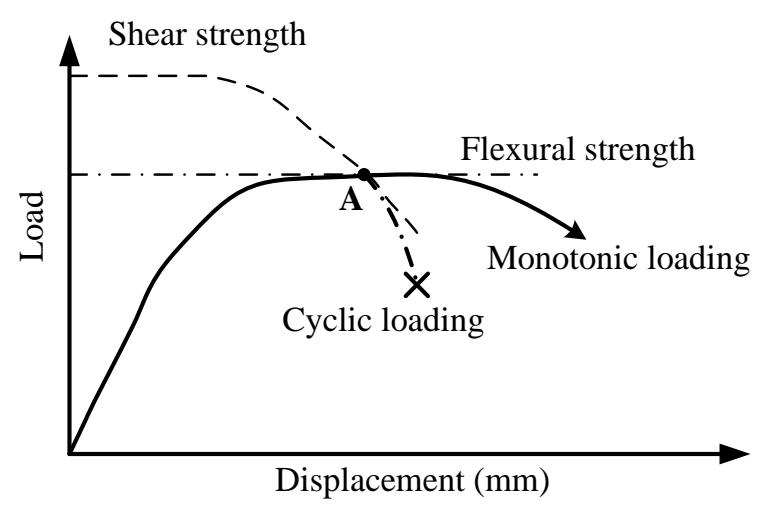

Figure 1: Shear failure after yielding of tension reinforcing bar. 


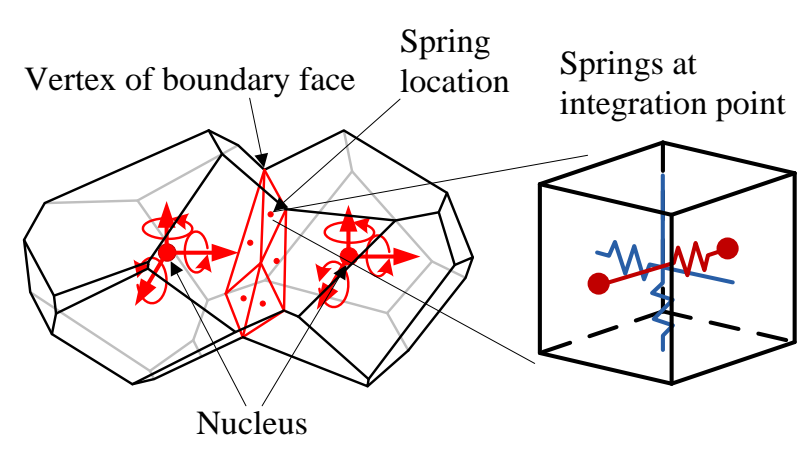

(a) 3-D rigid-body-spring-model.

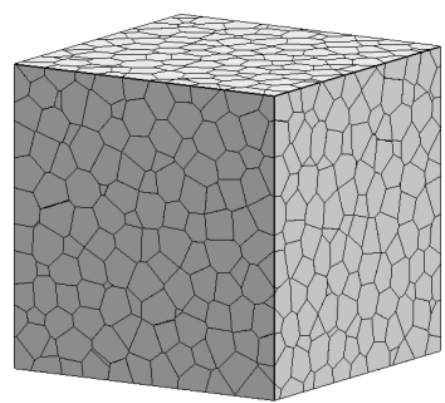

(b) Voronoi tessellation.

Figure 2: 3-D RBSM and Voronoi tessellation.

The reason of shear failure after flexural yielding of a RC member has been explained as that the shear strength gradually degrades with increasing displacement level and ultimately becomes smaller than the shear demand for development of the flexural strength, which leads to the decrease of load carrying capacity (Fig. 1). Corresponding to this failure mode, the relationship between degraded shear strength and displacement ductility (also known as shear strength degradation curve) was proposed by ATC seismic design guidelines [9] in the first time. Inspired by ATC design approach, some researchers modified the degradation curves of concrete shear resistant contribution such as the works by Ang [10], Wang [11], Priestley [12] and Ohe [13]. The method of shear strength degradation curve is used for the current seismic design of JSCE specification [3] to judge the failure mode of RC member.

Although it is particularly important to quantitatively investigate the shear strength degradation of a RC member, the degraded shear strengths, which are ordinarily larger than the flexural strength in initial loading stage, cannot be investigated by test load hysteresis loop (load hysteresis loop can only relect the flexural strength).

Thus, this study first presented a numerical method to evaluate shear strength degradation of $\mathrm{RC}$ member utilizing three dimensional Rigid-Body-Spring-Model (3-D RBSM). Then the behaviors of a RC column subjected to cyclic loading and repeated loading on one side were simulated by 3-D RBSM and the behaviors of the shear strength degradation were quantitatively evaluated. Moreover, the effect of loading history on the degradation rate of shear strength were shown. Finally, the reasonability of the numerical method was confirmed by comparing numerical shear strength degradation curve with previously statistically proposed degradation curves based on the test results.

\section{ANALYTICAL MODEL}

\subsection{3-D RBSM}

We have developed the 3-D RBSM [14] in order to quantitatively evaluate the mechanical responses including softening and localization fractures, and have shown that the model can well simulate the cracking and failure behaviors of RC members $[15,16]$. In RBSM, concrete is modeled as an assemblage of rigid particles interconnected by springs at their boundary surfaces (Fig. 2(a)). The crack development is affected by mesh design as cracks initiate and propagate through interface boundaries of particles. Therefore, a random geometry of rigid particles is generated by Voronoi tessellation (Fig. 2(b)), which can reduce mesh bias on the initiation and propagation of potential cracks.

The response of the spring model, which has one normal and two tangential springs, provides an insight into the interaction among the particles, which is different from models based on continuum mechanics. In this model, each rigid particle has three translational and three rotational degrees of freedom defined at the nuclei that define the particles according to the Voronoi tessellation. 


\subsection{Concrete material model}

The constitutive models for tension, compression and shear springs used in 3-D RBSM are constructed by uniaxial relationships. The details of the models and the related model parameters for monotonic loading analysis have been described in the research conducted by Yamamoto [14].

Moreover, by using the same model parameters, the models for cyclic loading analysis containing unloading and reloading paths, which regards the models for monotonic loading as the envelop curve, were developed [16].

Fig. 3(a) shows the typical hysteresis loop of the normal spring for cyclic loading. The unloading paths in the tension zone pass toward the point of stress $\sigma=-0.02 f_{c}{ }^{\prime} *\left(f_{c}{ }^{\prime} *\right.$ is the nominal concrete compressive strength) on the compression loading path. The reloading paths in the tension zone pass toward the start point of the unloading. The stiffness of the unloading in the compression zone is the initial elastic modulus $E$.

Fig. 3(b) shows the typical hysteresis loop of the shear spring. The stiffness of the unloading and reloading is the initial elastic modulus $G$. In addition, after the stress reaches zero on the unloading path, the stress keeps zero until the strain reaches the residual strain of the opposite sign.

\subsection{Reinforcing bar and bond models}

Reinforcing bar is modeled as a series of regular beam elements (Fig. 4) that can simulate the bending effects. In this model, the reinforcement can be freely positioned within the member, regardless of the mesh design of concrete [17]. At each beam node, two translational and one rotational degrees of freedom are defined by means of the springs. The reinforcement is attached to the concrete particles by zero-size link elements, which provide a load-transfer mechanism between a concrete particle and a beam node. A bi-linear model is assumed for the stress-stain relation of reinforcement. Crack development is strongly affected by the bond interaction between concrete and reinforcement of linked

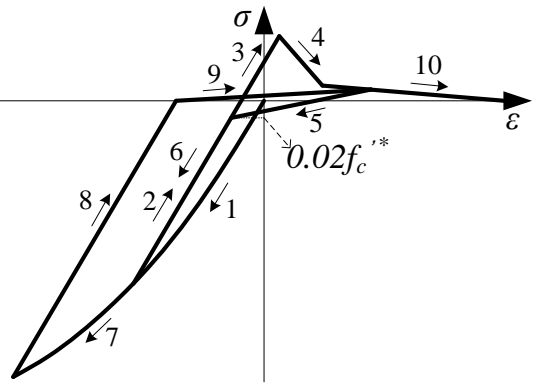

(a) Normal spring.

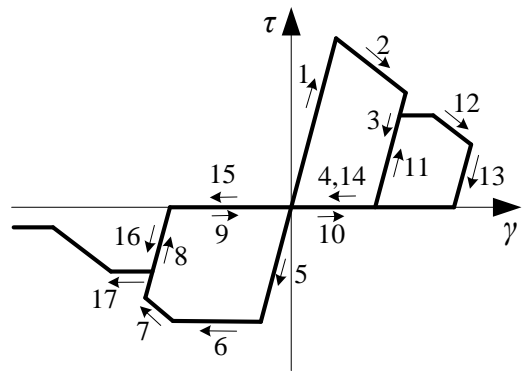

(b) shear spring ( $\sigma=$ constant).

Figure 3: Hysteresis of stress-strain relationship.

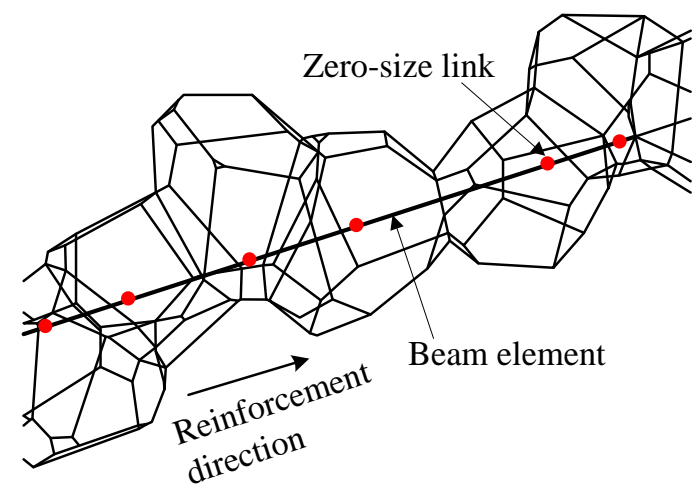

Figure 4: Reinforcing bar element arrangement.

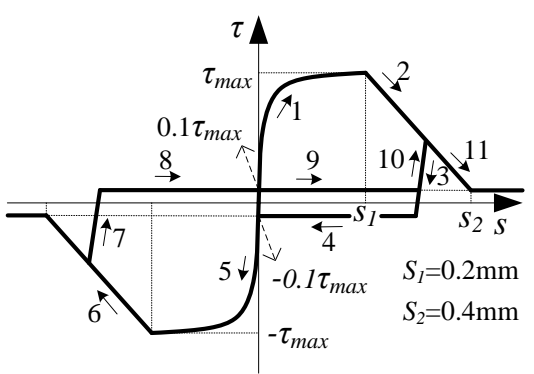

Figure 5: Bond stress-slip relationship. 


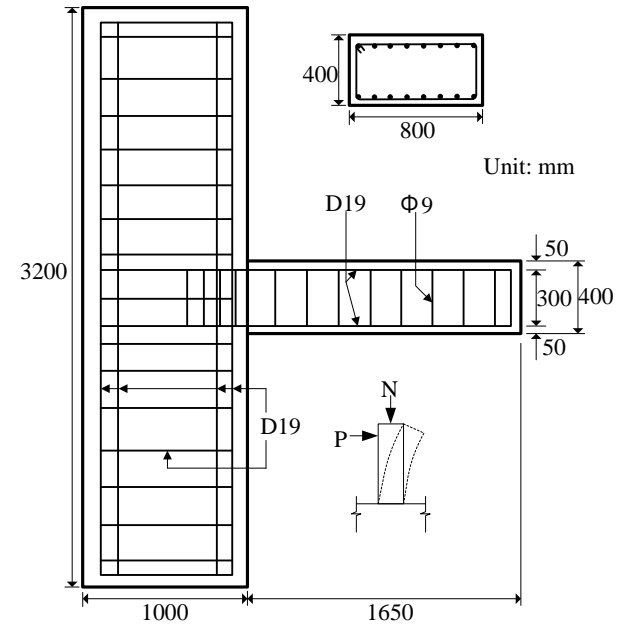

(a) Specimen outline.

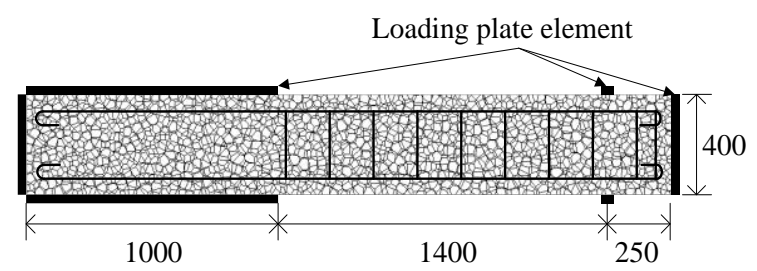

(b) Numerical model.

Figure 6: Specimen outline and numerical model.

element. After yielding of reinforcement, the hardening coefficient is assumed as 1/100. Fig. 5 shows the bond-stress relation. Up to the shear strength $\tau_{\max }$, the relation proposed by Suga [18] is applied and the relation proposed by CEB-FIB [19] is used for the post peak behavior. As the typical hysteresis loop, the stiffness of reloading and unloading is the initial secant stiffness of the $\pm 0.1 \tau_{\max }$ stress points. After the stress reaches the level of $\pm 0.1 \tau_{\max }$ on the unloading paths, the stress keeps this level until the slip reaches the residual slip of the opposite sign.

\section{SIMULATION OF SHEAR FAILURE AFTER FLEXURAL YIELDING OF TENSION REBAR OF A RC COLUMN}

In this chapter, the numerical result of shear failure after flexural yielding of a RC column simulated by 3-D RBSM was discussed [20].

\subsection{Numerical model}

The 3-D RBSM analyses of cyclic loading

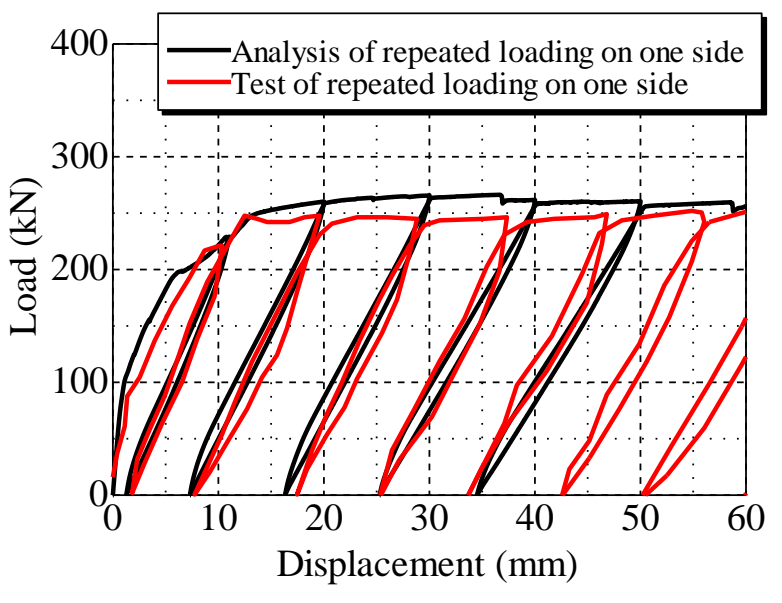

Figure 7: Load-displacement relationship of repeated loading on one side analysis.

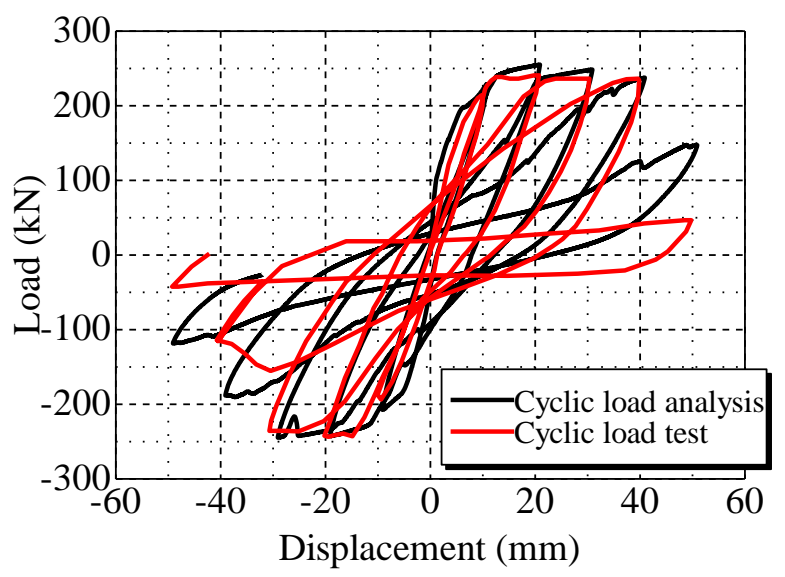

Figure 8: Load-displacement relationship of cyclic loading analysis.

and repeated loading on one side of the RC column tested by Oota [21] were conducted and it was confirmed that the analyses can accurately simulate the deformation behaviors until failure. The details of the objective RC column are shown in Fig. 6(a). The footing and the column were $1000 \mathrm{~mm}$ and $1650 \mathrm{~mm}$ in height, respectively. And the column had a cross section of $800 \mathrm{~mm} \times 400 \mathrm{~mm}$ with an effective depth of $350 \mathrm{~mm}$. The loading plate was $1400 \mathrm{~mm}$ high from the column base, namely the shear span-to-effective depth ratio was 4.0. Sixteen longitudinal reinforcing bars of D19 type were arranged with a concrete cover thickness of $50 \mathrm{~mm}$ (tension reinforcement ratio: $0.82 \%$ ). The stirrups of Ф9 type were arranged with a space of $200 \mathrm{~mm}$ in shear span (web reinforcement ratio: $0.08 \%$ ). 
The yield strengths of longitudinal reinforcing bars and stirrups were $365.5 \mathrm{Mpa}$ and $372.2 \mathrm{Mpa}$, respectively, and the compressive strength of concrete was $28.6 \mathrm{Mpa}$. Shear load $(P)$ was imposed by displacement control and the peak displacement of cyclic loading and repeated loading on one side were increased stepwise with the increment of yield displacement $\left(\delta_{y}\right)$, which was around $10 \mathrm{~mm}$ (each displacement level was repeatedly loaded ten loops). In addition, during the shear loading a1Mpa axial load $(N)$ was applied to the top of the column.

As a result of the test, under cyclic loading, the load carrying capacity of the column decreased at the displacement level of $-4 \delta_{y}$ as shear failure after flexural yielding occurred; under repeated loading on one side, however, the original load carrying capacity could be maintained until the displacement level of $+8 \delta_{y}$.

In order to reduce computing time, onequarter model (cross section: $200 \mathrm{~mm} \times 400 \mathrm{~mm}$ ) of the RC column was constructed (Fig. 6(b)), and the average element size of concrete rigid particles was $30 \mathrm{~mm}$, which was recommended by Yamamoto [14]. And the reinforcing bars were modeled by beam and zero-link elements discretely. The footing area was fixed by three plates (rigid prism) and the axial load was applied to the plate on the top of the column. By controlling displacement, cyclic loading or repeated loading on one side was imposed on the shear loading plates $(1400 \mathrm{~mm}$ from footing column interface). Moreover, as the test load hysteresis under ten loops of repeated loading overlapped virtually, in 3-D RBSM analysis, one load loop will be simulated for each displacement level.

\subsection{Analytical result}

Fig. 7 illustrates the load-displacement relationships for repeated loading on one side (test and 3-D RBSM analysis). Since onequarter model was applied, the numerical load in this study has been magnified four times the original output. Consequently, the analytical curve agreed well with the experimental result, where the RC column could maintain the original load carrying capacity until the

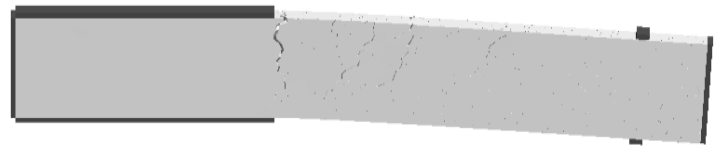

(a) Deformation behavior at $+1 \delta_{y}$.

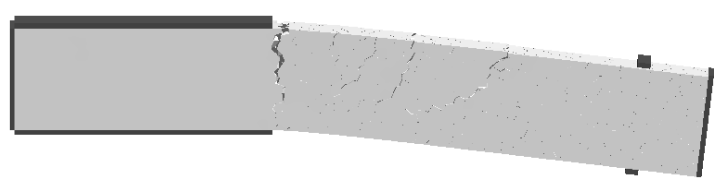

(b) Deformation behavior at $+2 \delta_{y}$.

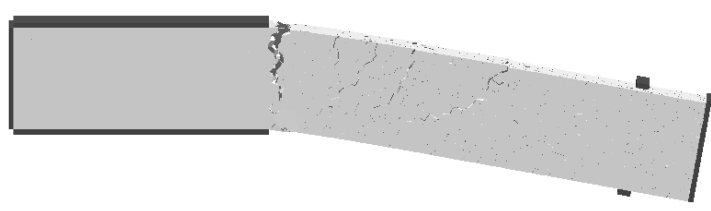

(c) Deformation behavior at $+3 \delta_{y}$.

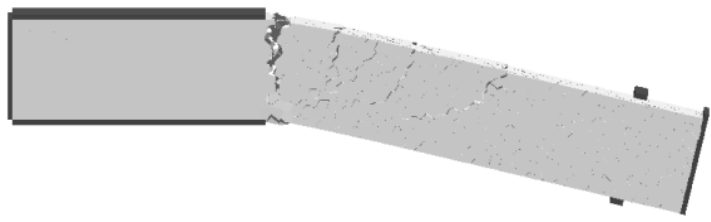

(d) Deformation condition at $+4 \delta_{y}$.

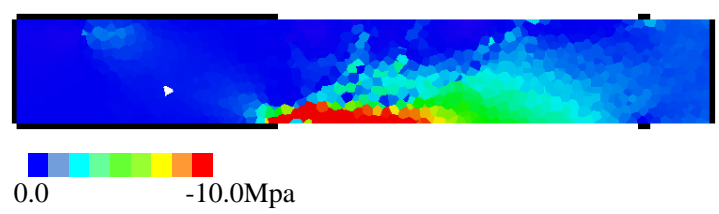

(e) Axial compressive stress distribution at $+4 \delta_{y}$.

Figure 9: Deformation behaviors and axial compressive stress distribution (repeated loading on one side).

deformation of $+5 \delta_{y}$.

Fig. 8 shows the load-displacement relationships for cyclic loading (test and 3-D RBSM analysis) and it was observed that the spindled shape of load-displacement curves at initial load stage changed to inverse S-shape with the increase of displacement level, which signified a development of shear deformation, and the load carrying capacities decreased with a high rate at the deformation of $-4 \delta_{y}$.

The numerical deformation behaviors (deformation was magnified eight times the original output in this study) for each displacement level and the axial compressive 
stress distribution in the column central section (at the deformation of $+4 \delta_{y}$ ) of repeated loading on one side are illustrated in Fig. 9. It was observed that the flexural cracks first initiated near the footing-column joint at the initial deformation of $+1 \delta_{y}$ (Fig. 9(a)). Then, the flexural cracks propagated toward the compression zone and the crack widths became larger with the increase of displacement level (Fig. 9(b), (c), (d)). At the deformation of $+4 \delta$, the localization of compressive stress due to bending was confirmed (Fig. 9(e)), which indicated that bending deformation was dominant to the behavior of RC column under repeated loading on one side.

Fig. 10 gives the numerical deformation behaviors and the axial compressive stress distribution for cyclic loading. Until the deformation of $+2 \delta_{y}$, same flexural crack propagation as that under repeated loading on one side was observed (Fig. 10(a), (b)). At the displacement of $+3 \delta_{y}$, however, shear deformation became notable, that is, diagonal shear cracks generated at footing-column joint (Fig. 10(c)), which was different from that under repeated loading on one side (Fig. 9(c)). After that, the shear deformation rapidly developed and became remarkable, which resulted in the shear failure of the RC column at the displacement of $+4 \delta_{y}$ (Fig. 10(d)). Moreover, as shown in Fig. 10(e), it was noted that the compressive stress intensively distributed along the diagonal shear cracks at the displacement of $+4 \delta_{y}$, which indicated that the shear deformation behavior became dominant at the ultimate stage.

Based on the above numerical result, it was confirmed that 3-D RBSM cannot only accurately simulate the bending deformation under repeated loading on one side but also the deformation transformation from bending to shear due to cyclic loading of a RC member.

\section{EVALUATION OF SHEAR STRENGTH DEGRADATION}

\subsection{Evaluation approach of shear strength degradation}

The reason of shear failure after flexural

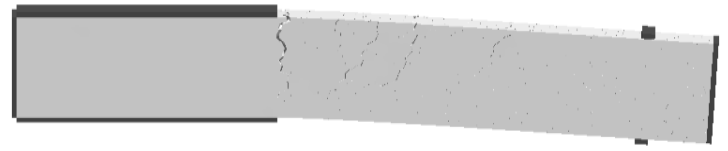

(a) Deformation behavior at $+1 \delta_{y}$.

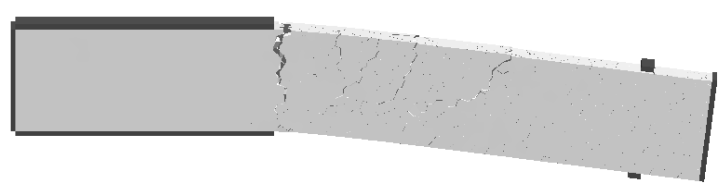

(b) Deformation behavior at $+2 \delta_{y}$.

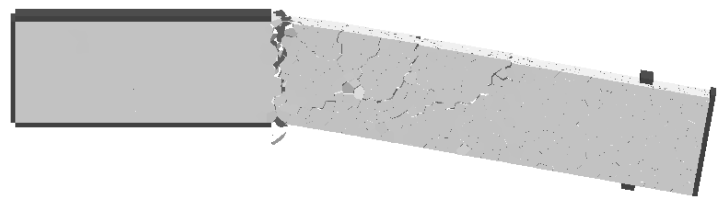

(c) Deformation behavior at $+3 \delta_{y}$.

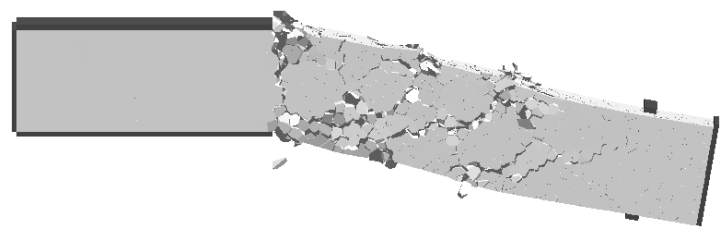

(d) Deformation behavior at $+4 \delta_{y}$.

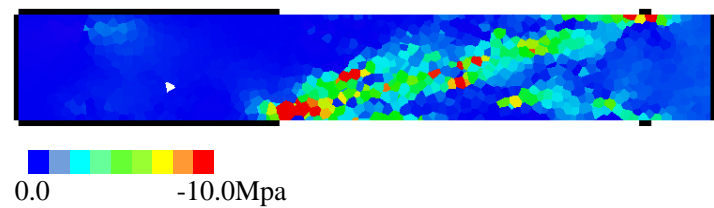

(e) Axial compressive stress distribution at $+4 \delta_{y}$.

Figure 10: Deformation behaviors and axial compressive stress distribution (cyclic loading).

yielding of a RC member under cyclic loading has been explained as that the shear strength gradually degrades and ultimately becomes smaller than the flexural strength with the increase of displacement level. And it is significant to seismic deformation-based design to quantitatively evaluate the degraded shear strengths after each load cycle. Considering that the degraded shear strengths cannot be directly investigated by test load hysteresis as the test load carrying capacity cannot exceed the flexural strength, in this chapter, we proposed a numerical approach for quantitative evaluation of shear strength 
degradation by using 3-D RBSM.

The numerical approach for evaluation of the degraded shear strength after first load cycle (cyclic loading condition) of a RC member will be described by Fig. 11. The black load curve represents the loaddisplacement relationship obtained by cyclic loading analysis of a $\mathrm{RC}$ member and it is obvious that the load carrying capacity cannot exceed the flexural strength $\left(P_{u}\right)$. Thereby, the degraded shear strength $\left(V_{u}\right)$ after first load cycle, which is ordinarily larger than the flexural strength $\left(P_{u}\right)$, cannot be directly investigated. Thus, an approach that makes the flexural strength $\left(P_{u}\right)$ larger than the original shear strength $\left(V_{u}\right)$ is desired for evaluation by numerical load hysteresis. And this is noted that can be achieved in 3-D RBSM analysis at the end of the first load cycle (point A) without affecting the degraded shear strength $\left(V_{u}\right)$ by the way increasing the yield stress of longitudinal reinforcing bars, according to the evaluation formulae of flexural and shear strengths expressed by Eq. (1)-(4), utilized in JSCE standard specification [3]. It was apparent that the change of the yield stress of longitudinal reinforcement only has influence on the flexural strength, which can also be acknowledged in other design guidelines [1].

$$
\begin{aligned}
& P_{u}=f_{y} A_{s}(d-0.4 x) / a \\
& V_{u}=V_{c}+V_{s} \\
& V_{c}=0.20 f_{c}{ }^{1 / 3} \rho_{t}{ }^{1 / 3} d^{-1 / 4}(0.75+1.4 /(a / d)) b_{w} d \\
& V_{s}=A_{w} f_{y w}(\sin \alpha+\cos \alpha)
\end{aligned}
$$

Where, the term $P_{u}$ is the flexural strength under primary tension failure; the term $f_{y}$ is the yield stress of longitudinal reinforcement; the term $d$ is the column effective depth; the term $x$ is the depth of the equivalent rectangular stress block; the term $a$ is the length of shear span; the term $V_{u}$ is the total shear strength; the term $V_{c}$ is the shear strength provided by concrete contribution; the term $V_{s}$ is the shear resistance sustained by web reinforcement; the term $f_{c}$ ' is the nominal concrete compression strength; the term $\rho_{t}$ is the tension reinforcement ratio; the term $b_{w}$ is the column width; the term $A w$ is the area of a set of web reinforcement; the term $f_{y w}$ is the yield strength

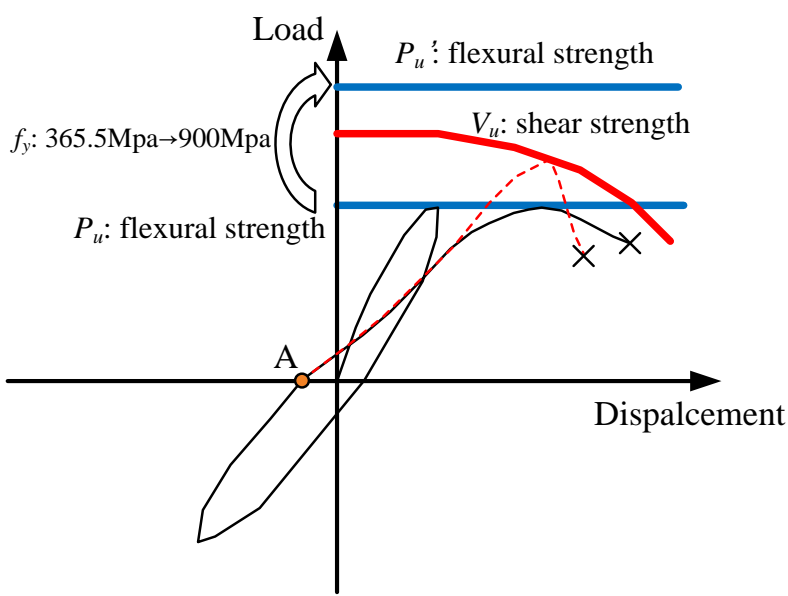

Figure 11: Numerical approach for evaluation of the degraded shear strength after first load cycle.

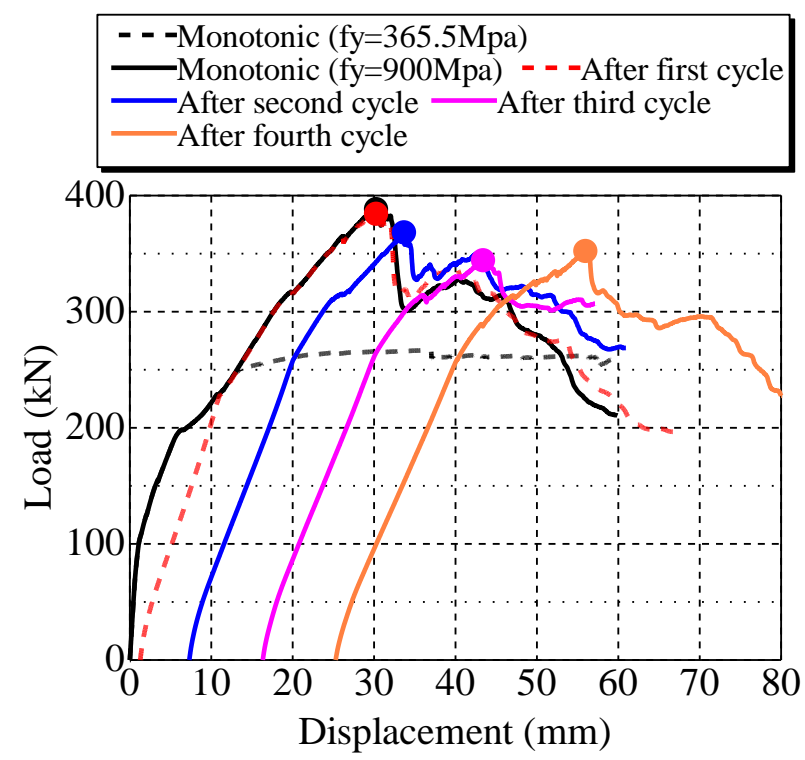

Figure 12: Load-displacement relationships for evaluation of the degraded shear strengths after each load cycle (repeated loading on one side).

of web reinforcement; the term $\alpha$ is the diagonal crack angle to column's axis.

In this study, the flexural strength $\left(P_{u}\right)$ was increased to an extremely larger level $\left(P_{u}{ }^{\prime}\right)$ than the original shear strength $\left(V_{u}\right)$ at the end of first load cycle (Fig. 11), and after that a monotonic loading (dotted red curve) was imposed to the RC column until shear failure. The peak load obtained by the monotonic loading was regarded as the degraded shear strength after first load cycle. Similarly, the degraded shear strengths after each load cycle were further investigated, which allows an 
evaluation of the relationship between degraded shear strength and displacement level.

\subsection{Result of degraded shear strengths after each load cycle}

Based on the proposed numerical approach, the 3-D RBSM analyses for evaluation of the degraded shear strengths after each load cycle of repeated loading on one side and cyclic loading were carried out. The yield stresses of longitudinal reinforcing bars were increased from the original $365.5 \mathrm{Mpa}$ to $900 \mathrm{Mpa}$ at the end of a certain load cycle in order to obtain an extremely large flexural strength.

The analytical load-displacement curves locating in the first quadrant for evaluation of the degraded shear strengths of repeated loading on one side and cyclic loading are plotted in Fig. 12 and Fig. 13, respectively. In addition, the load-displacement curves of the monotonic loading analysis with large rebar yield stress $\left(f_{y}=900 \mathrm{Mpa}\right)$ (for reference of the original shear strength) and the monotonic loading analysis with normal rebar yield stress $\left(f_{y}=365.5 \mathrm{Mpa}\right.$ ) (for reference of the flexural strength) are also illustrated. The peak loads after each load cycle were marked, which were regarded as the degraded shear strengths (the load at the displacement of $60 \mathrm{~mm}$ was regarded as the peak load for the case after fourth load cycle of cyclic loading).

As a consequence, for the shear strength degradation due to repeated loading on one side (Fig. 12), it was noted that the shear strength degraded with the increasing number of load cycles but it was still larger than the flexural strength (after fourth load cycle), thereby the load carrying capacity could be maintained by the RC column (Fig. 7); for the shear strength degradation due to cyclic loading (Fig. 13), it was found that the shear strength decreased with a much larger rate than that under repeated loading on one side with the increasing number of load cycles, and it significantly decreased and became much smaller than the flexural strength after fourth load cycle, thereby the load carrying capacity of the RC column was reduced (Fig. 8).

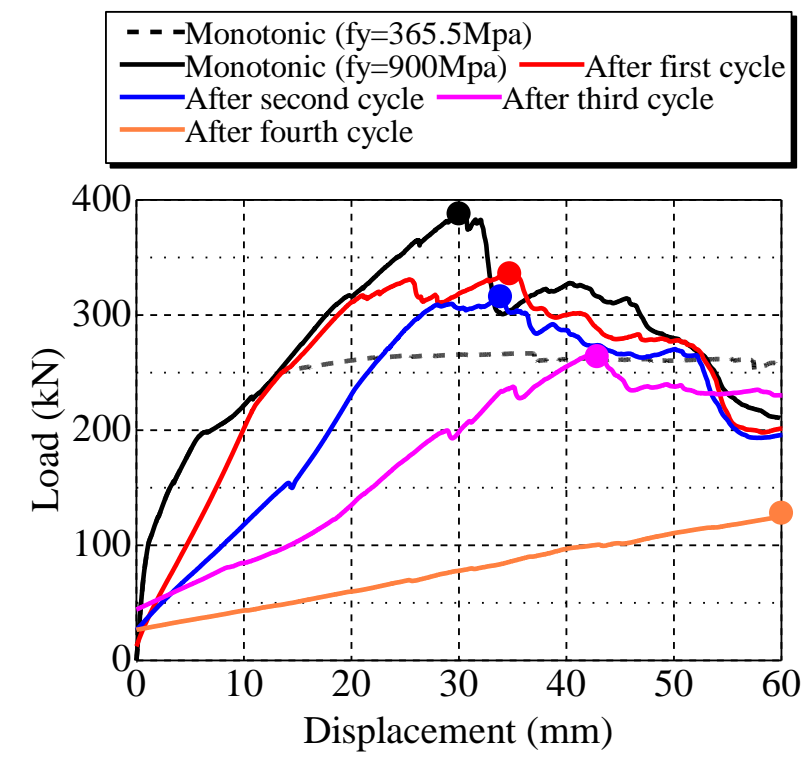

Figure 13: Load-displacement relationships for evaluation of the degraded shear strengths after each load cycle (cyclic loading).

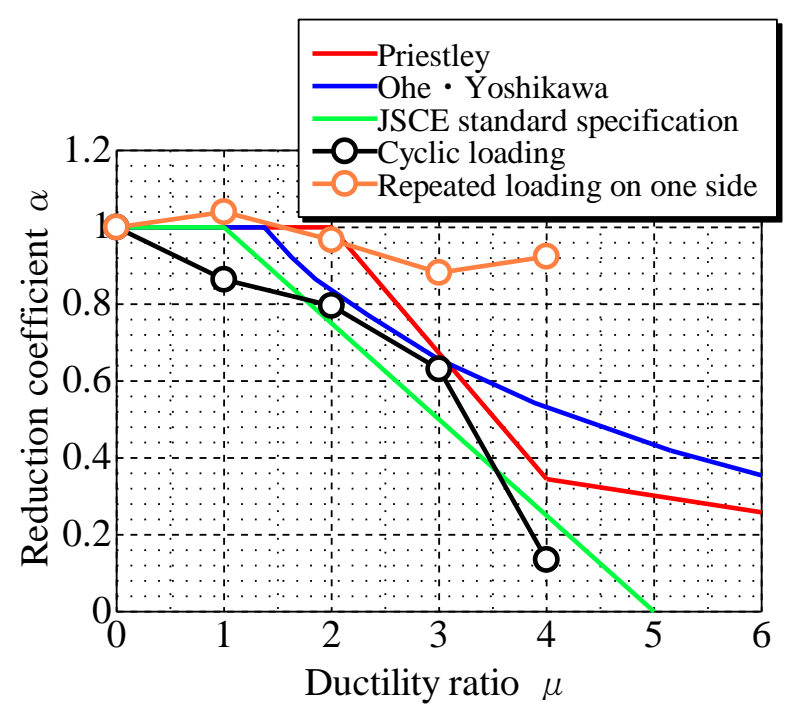

Figure 14: Shear strength degradation curves.

It was apparent that based on the proposed numerical approach the different behaviors of shear strength degradation under repeated loading on one side and cyclic loading could be quantitatively evaluated.

\subsection{Evaluation of shear strength degradation curves}

Many researches [3, 12, 13] have proposed shear strength degradation curves of RC member under cyclic loading based on the statistical process of test results (herein, the 
shear strength represented is the concrete shear resistant contribution $V_{c}$ ), and they are plotted in Fig. 14 (reduction coefficient $\alpha$ means the ratio of the degraded concrete contribution to the original strength obtained by monotonic loading test).

Regarding the numerical evaluation of the degraded concrete contributions of the RC column used in this study, they were calculated by subtracting the web reinforcement contribution $V_{s}$ from the obtained degraded shear strengths calculated in chapter 4.2. And the web reinforcement contribution could be evaluated by the difference of the shear strengths between the RC columns with and without web reinforcement by 3-D RBSM monotonic loading analyses with large yield stress of rebar.

By this way, the numerical degradation curves of concrete contributions of repeated loading on one side and cyclic loading of the RC column were obtained (Fig. 14). As a result, compared with the previous degradation curves for design, which were summarized by test results, it was noted that the numerical degradation behavior under cyclic loading presented the same trend and the degradation rate with increasing deformation ductility was slightly larger than the design curves proposed by Priestley and Ohe - Yoshikawa. In addition, the degradation rate of repeated loading on one side was extremely slow, which was very different from that under cyclic loading.

Based on the above result, it was clarified that the proposed evaluation method by 3-D RBSM for shear strength degradation of RC member is applicable and helpful.

\section{CONCLUSIONS}

(1) The behaviors of repeated loading on one side and cyclic loading tests for a RC column were accurately simulated by $3-\mathrm{D}$ RBSM. Under cyclic loading, shear deformation gradually became dominant and ultimately shear failure after flexural yielding of tension reinforcing bars occurred at small deformation ductility, whereas bending deformation was dominant to the behavior under repeated loading on one side.

(2) The numerical method by 3-D RBSM for quantitatively evaluation of shear strength degradations due to cyclic loading and repeated loading on one side was proposed.

(3) Based on the shear strength degradations obtained by 3-D RBSM, it was found that shear strength degraded rapidly with increasing number of load cycles under cyclic loading, whereas it was reduced slowly under repeated loading on one side, thereby shear failure occurred in cyclic loading.

(4) Comparing with the degradation curves proposed by statistical process of test results, the numerical degradation curve of cyclic loading shows same trend, which proves the applicability of the numerical method for evaluation of shear strength degradation by 3D RBSM.

\section{REFERENCES}

[1] Building code requirements for structural concrete and commentary, ACI 318-05, and ACI 318R-11, American Concrete Institute (ACI), Farmington Hills, 2011

[2] CEB model code for seismic design of concrete structures, No. 165, 1985.

[3] Standard Specifications for ConcreteDesign. JSCE, 2012.

[4] Park, R.1982. Ductility of Square-Confined Concrete Columns, ASCE ST4, Vol. 108, No. 4: 929-950.

[5] Saatcioglu, M. 1991. Deform Ability of Reinforced Concrete Columns, ACI Struct. J., Vol. 127: 421-452.

[6] Panagiotakos, B., T. and Fardis, N., M. 2001. Deformations of Reinforced Concrete Members at Yieldingand Ultimate, ACI Struct. J., Vol. 98(2): 135148.

[7] Priestley, M. J. N.1981. Ductility of Spirally-Confined Concrete Columns, ASCE ST1, Vol. 107, No. 1: 181-202.

[8] Ishibashi, T., Nakayama, Y. and Tsuyoshi, T. 2001. Failure Mode of Reinforced Concrete Column without Hoop 
Reinforcement, Journal of JSCE, No. 676, V-51: 13-18. (in Japanese)

[9] Seismic retrofitting guidelines for highway bridges, Applied Technology Council (ACT6-2), Redwood City, Calif., 1983.

[10] Ang, B. G., Priestley, M. J. N. and Paulay, T. 1989. Seismic Shear Strength of Circular Reinforced Concrete Columns, ACI Struct. J., 86(1), 45-59.

[11] Wong, Y. L., Paulay, T. and Priestley, M. J. N. 1993. Response of Circular Reinforced Concrete Columns to Multidirectional Seismic Attack, ACI Struct. J., 90(2), 45-59.

[12] Priestley, M. J. N., Seible, F. and Carvi, G. M. 1996. Seismic Design of Retrofit of Bridges, A Wiley-Interscience Publication.

[13] Ohe, R. and Yoshikawa, H. 2002. Study on Shear Strength Degradation of Single Reinforced Concrete Columns under Repeated Large Deformation, Journal of JSCE, No. 711, V-56: 59-71. (in Japanese)

[14] Yamamoto, Y., Nakamura, H., Kuroda, I. and Furuya, N. 2008. Analysis of Compression Failure of Concrete by Three Dimensional Rigid Body Spring model, Journal of JSCE, Vol. 64: 612630. (in Japanese)

[15] Gedik, Y. H., Nakamura, H., Yamamoto, Y., Kunieda, M. and Furuya, N. 2011. Analysis of Compression Failure of
Concrete by Three Dimensional Rigid Body Spring model, Cement \& Concrete Composites, Vol. 33: 978-991.

[16] Yamamoto, Y., Nakamura, H., Kuroda, I. and Furuya, Nobuaki. 2014. Crack Propagation Analysis of Reinforced Concrete Wall under Cyclic Loading Using RBSM, European Journal of Environmental and Civil Engineering, Vol. 18(7-8): 780-792.

[17] Bolander, JE. and Hong, GS. 2002. RigidBody-Spring Networks Modeling of Prestressed Concrete Members, ACI Struct. J., Vol. 99(5): 595-604.

[18] Suga, M., Nakamura, H., Higai, T. and Saito, S. 2001. Effect of Bond Properties on the Mechanical Behavior of RC Beam, Proceedings of Japan Concrete Institute, Vol. 23(3): 295-300. (in Japanese)

[19] Comite Euro-International du Beton. 1990. CEB-FIB Model Code 1990 First Draft, $C E B$, Paris.

[20] Nakamura, H., Furuhashi, H., Yamamoto, Y. and Miura, T. 2014. Evaluation of Shear Strength Degradation of RC Member Subjected to Cyclic Loading, Journal of JSCE, Vol. 71, No. 1: 48-57. (in Japanese)

[21] Ohta, M. 1979. An Experimental Study on the Behavior of Reinforced Concrete Bridge Piers under Cyclic Loadings. Journal of JSCE, No. 292: 65-74. (in Japanese) 